Article

\title{
El castillo de la pureza. Concepto de Hogar Mundo y la irrupción de los Nuevos Puritanismos en el contexto de la pandemia de COVID 19
}

\author{
Felipe Gaytán Alcalán', Ricardo Bernal ${ }^{2}$
}

\begin{abstract}
Resumen. Este texto pretende mostrar el surgimiento de una nueva dimensión social identificada como Hogar-Mundo y cómo gracias a esta cobran fuerza Nuevos Puritanismos ligados a lo religioso que abonan al campo de los neoconservadurismos, pero simultáneamente se distancian de ellos desde el ámbito privado. El trabajo toma como referencia lo ocurrido en México durante la pandemia de COVID 19. Metodológicamente este es un ejercicio interpretativo de una representación social tanto del hogar como de lo que identificamos aquí como Nuevos Puritanismos a partir de datos, informaciones y sucesos que permiten perfilar esta realidad sociológica.
\end{abstract}

Palabras clave: Hogar-Mundo, Nuevos Puritanismos, neoconservadurismo, COVID-19, laicidad.

\begin{abstract}
This text tries to show the emergence of a new social dimension identified as Home-World and how through its New Puritanism linked to the religious sphere gain strength that although they resemble the field of neo-conservatisms, but simultaneously distance themselves from them from the field private. The work takes as a reference what happened in Mexico during the COVID 19 pandemic. Methodologically this is an interpretive exercise of a social representation of both the Home-World and what we identify here as New Puritanism based on data, information and events that allow outline this sociological reality.
\end{abstract}

Keywords: Home-World, New Puritanism, neo-conservatisms, COVID-19, laicity.

En una existencia como la mía no se podrían hacer previsiones: nunca sé qué puede ocurrir en la próxima media hora, no sé imaginarme una vida totalmente hecha de mínimas alternativas bien circunscritas, sobre las cuales se pueden hacer apuesta.

(Italo Calvino, 1980: 11)

\footnotetext{
${ }^{1}$ Facultad de Humanidades, Universidad La Salle México, Ciudad de México, México. ORCID ID: orcid.org/ 0000-0002-1409-017X. Email: elipe.gaytan@lasalle.mx

${ }^{2}$ Facultad de Humanidades, Universidad La Salle México, Ciudad de México, México. ORCID ID: http://orcid. org/0000-0003-2165-9595. Email: ricardo.bernal@lasalle.mx
}

Copyright $\odot 2021$ The Author(s). Open Access. This in an open access article published by Firenze University Press (www.fupress.net/index.php/ccselap) and distributed under the terms of the Creative Commons Attribution 4.0 International License. The Creative Commons Public Domain Dedication waiver applies to the data made available in this article, unless otherwise stated. 


\section{Introducción}

La pandemia trajo consigo cambios radicales en la transformación del tiempo y el espacio social en el que se desarrollaban las actividades humanas. Uno de estos cambios ha sido el surgimiento de lo que aquí denominamos Hogar-Mundo, un concepto que refiere a la fusión de las esferas pública, privada e íntima en el interior de la casa.

La actual situación de contingencia sanitaria no sólo modificó las dinámicas económicas o laborales (Weller et. al, 2020), también tuvo un impacto importante sobre la dimensión moral-religiosa en las relaciones familiares. Las características del nuevo Hogar-Mundo favorecen un ambiente en el que las creencias religiosas y valores morales de lo(a)s jefe(a)s del hogar tienden a imponerse sobre la elección libre y la opinión del resto de los integrantes de la familia con efectos especialmente negativos para mujeres, niños. niñas y adolescentes $^{3}$ y para la comunidad LGBTTTQI. ${ }^{4}$

La prevalencia de lo privado como esfera dominante ante lo público e íntimo, ha promovido que las creencias religiosas y morales se vuelvan filtros que regulan la comunicación de la calle en el hogar. Esto ha propiciado la irrupción de nuevos puritanismos caracterizados por el predominio moral y religioso sobre el espacio privado, excluyendo lo que a su juicio se considera obsceno o contrario a las creencias en el hogar. Tres características los definen:

i) Evitar la contaminación del exterior (sanitaria, social y moral);

ii) Regulación de la conciencia individual en el ámbito familiar evitando el contagio por asociación;

iii) Reafirmar la cultura de la cancelación contra aquellos que provocan el mal moral.

Los nuevos puritanismos si bien poseen afinidad con los neoconservadurismos religiosos y hasta los fundamentalismos, tienen marcadas diferencias. Los primeros no buscan protestar en el espacio público por la ampliación de los derechos que, sobre la vida, el cuerpo y la familia se han alcanzado como sí lo han hecho los neoconservadores (Kuhar \& Patternote, 2018). Ellos simplemente los cancelan en el espacio privado. Para los nuevos puritanos se puede vivir sin religión, pero no sin sermones. Ellos no abogan por el pánico moral ellos juegan con la cultura de la cancelación.

A partir de lo ocurrido durante la pandemia por SARS-CoV 2 en México, este texto pretende mostrar el surgimiento de una nueva dimensión social identificada como HogarMundo y cómo gracias a esta cobran fuerza nuevos puritanismos ligados a lo religioso que abonan al campo de los neoconservadurismos, pero simultáneamente se distancian de ellos desde el ámbito privado. Metodológicamente este es un ejercicio interpretativo de

\footnotetext{
${ }^{3}$ Según la Red Nacional de Refugios A.C (RNR) en México entre marzo y junio de 2020 atendió $81 \%$ más casos de mujeres junto con sus hijas e hijos debido a situaciones de violencia. Redacción (23 de julio 2020). La atención en refugios para mujeres subió $81 \%$ en los meses de confinamiento. Revista Expansión. Recuperado de: https://politica.expansion.mx/mexico/2020/07/23/la-atencion-en-refugios-para-mujeres-subio-81-en-los-meses-de-confinamiento

${ }^{4}$ El 17 de mayo en la Conferencia informativa diaria del Gobierno Federal mexicano la titular del Consejo Nacional para Prevenir la Discriminación (Conapred) señaló que entre las denuncias recibidas durante la pandemia daban cuenta de una mayor exposición a la violencia para las personas de la comunidad LGBTTTQI debido a los prehuicios que existían en los hogares. Consejo Nacional para Prevenir la Discriminación. (13 de septiembre 2020). 17 de Mayo, Día Nacional de Lucha contra la Homofobia. Recuperado de: http://www.conapred.org. $\mathrm{mx} /$ index.php? contenido $=$ noticias $\&$ id $=3153 \&$ id_opcion $=\& o p=447$
} 
una representación social tanto del hogar como de lo que identificamos aquí como Nuevos Puritanismos a partir de datos, informaciones y sucesos que permiten perfilar esta realidad sociológica.

\section{Concepto Hogar-Mundo: el quiebre de la distinción público-privado-íntimo}

En el famoso desenlace del Mago de Oz (1939), el personaje de Dorothy -protagonizado por Judy Garland- debe repetir en tres ocasiones la frase "No hay mejor lugar que el hogar" para volver a casa luego de haber vivido una aventura llena de peligros. Desde entonces, la expresión se ha usado para subrayar que los riesgos del exterior pueden ser contenidos en el ámbito del hogar, frontera de la seguridad frente a la amenaza del mundo y un espacio privilegiado en el que la convivencia con los comunes (familia o conocidos) establece en apariencia lazos de solidaridad. Sin embargo, esta concepción suele dejar de lado que a lo largo de la historia el ámbito de lo doméstico ha sido un espacio propicio para las jerarquías, la dominación y la violencia. ${ }^{5}$

Como en otros países, en México algunas autoridades acompañaron el llamado a quedarse en casa (\#QuedateEnCasa) ante la emergencia sanitaria con una visión romantizada en la que el hogar fue presentado como fuente de protección primaria. Así, por ejemplo, el presidente Andrés Manuel López Obrador reivindicó de manera permanente a la familia como la principal institución para el cuidado de los adultos mayores e incluso polemizó con quienes argumentaron que las cifras de violencia de género aumentaron durante la pandemia. ${ }^{6}$ De igual forma, el hogar ha sido presentado como equivalente de la familia cuando en realidad existen hogares que no son familiares y familias que no comparten un hogar. Según datos del INEGI en México 11\% de los hogares no están conformados por lazos consanguíneos ni de parentesco. Estos hogares se integran por conocidos que comparten un espacio común, personas que comparten la renta o simplemente acuerdan por razones económicas, de afinidad amistosa o comunitaria vivir juntos en un espacio.

Hogar entonces tiene múltiples acepciones que incluyen desde lo económico, social o cultural.

a) Unidad económica referida a la cohabitación de personas que comparten recursos para resolver necesidades sin que implique un parentesco. (Sánchez Bravo, 2015, p. 192).

\footnotetext{
${ }^{5}$ Aunque en los últimos dos siglos y medio se han registrado mutaciones importantes en las dinámicas familiares y en la composición de los hogares, en prácticamente todo el mundo las cifras de violencia intrafamiliar, violencia de género y violencia en el hogar son preocupantes (Soto et al., 2003). ONU Mujeres ha advertido que el contexto de la pandemia por SARS-CoV 2 favorece el aumento de la violencia en el hogar. Naciones Unidas (21 de septiembre 2020). Víctimas de violencia doméstica atrapadas durante la pandemia. Recuperado de: https://www. un.org/es/coronavirus/articles/un-supporting-trapped-domestic-violence-victims-during-covid-19-pandemic ${ }^{6}$ Para dar tan sólo un ejemplo. En una alocución polémica el 23 de marzo de 2020 en la conferencia matutina diaria el mandatario mexicano afirmó: "A veces no gusta mucho porque, también con razón, se quiere cambiar el rol de las mujeres y eso es una de las causas, es una de las causas justas del feminismo, pero la tradición en México es que las hijas son las que más cuidan a los padres, nosotros los hombres somos más desprendidos, pero las hijas siempre están pendientes de los padres, de los papás, de las mamás.... Entonces, cuidamos, por tradición, por costumbre, porque la familia mexicana es la institución más importante de seguridad social que existe, es familia fraterna. Bueno, eso nos ha ayudado". Gobierno de México (23 de marzo 2020). Conferencia de prensa del presidente Andrés Manuel López Obrador, del 23 de marzo de 2020. Recuperado de: https://www.gob.mx/presidencia/ galerias/conferencia-de-prensa-del-presidente-andres-manuel-lopez-obrador-del-23-de-marzo-de-2020.
} 
b) Estadísticamente se identifica al hogar como un unidad doméstica en el un grupo de personas q comparten un espacio y los gastos derivados de este. Pueden o no ser familiares. Para efectos estadísticos una persona que vive sola constituye un unidad doméstica (INEGI, 2017).

c) Hogar es un espacio de relaciones sociales primarias de personas con afinidades de parentesco, económicas, culturales o religiosas (Sánchez Bravo, 2015, p. 194).

d) Espacio donde las personas llevan a cabo su vida privada y resuelven sus necesidades primarias (Sofsky, 2009, p. 53).

Lo que aquí se denomina Hogar-Mundo se inscribe en la lógica de los dos últimos incisos que refieren a un espacio de relaciones primarias por afinidad donde se lleva a cabo la vida privada y la resolución de necesidades.

Aunque este concepto tiene una afinidad semántica con el de Sistema-Mundo de Immanuel Wallerstein (2005) y con el de Ciudad-Mundo de Marc Augé (2007), tiene su propia lógica epistémica y conceptual que se aleja de ellos. Wallerstein plantea desde una perspectiva post-marxista, el Sistema-Mundo como una zona integrada de actividades e instituciones que obedecen a marcos sistémicos en el contexto de una economía-mundo capitalista (Wallerstein, 2005, p. 32). En tanto el concepto de Ciudad-Mundo de Augé refiere al proceso de urbanización que se extiende por el territorio, donde la movilidad, las formas de ser y pensar están ligadas a lo que la vida urbana pauta para todos los individuos. La Ciudad-Mundo es la manera en que la vida social urbana se ha globalizado borrando en gran parte las fronteras con lo rural e incluso con lo natural (Augé, 2007, pp. 25-27). Por su parte, el Hogar-Mundo hace referencia a una circunstancia particular que se configuró durante la pandemia, aun cuando sus consecuencias sociales y simbólicas muy probablemente terminarán prolongándose por más tiempo.

De manera similar a la fuerza que describe John Austin (1998) en los actos de habla donde las palabras tienen una repercusión sobre la percepción de la realidad y crean a su vez nuevas realidades, la consigna \#QuedateEnCasa se convirtió en un acto icónico cuya fuerza dibujó un espacio vital de salvación y fijó una representación social en la que la mayoría de las relaciones sociales y económicas se llevarían a cabo dentro de cuatro paredes. Al igual que el acto de habla, el acto icónico exterioriza los sentimientos, el pensamiento y la acción a través de una imagen (Bredekamp, 2017, p. 35). Mediante de la imagen del hogar se ha fijado con fuerza el sentido de protección y salvaguarda del grupo. Tanto el sentir, como el pensar y el actuar de la vida social, laboral, lúdica, amorosa se han traducido en la representación suprema del espacio privado, elevando una barrera de seguridad frente a la amenaza de estar expuesto a la contingencia sanitaria y el riesgo de convivir con otros en la calle cuyo acto icónico representa lo opuesto al hogar.

A pesar de que el hogar ha formado parte de nuestra cotidianidad de manera permanente, en las sociedades modernas ha sido relegado a un papel secundario en la articulación de la vida social. Desde el siglo XVIII el espacio público trastocó profundamente las dinámicas sociales (Habermas, 1989), mientras que el espacio privado comenzó a verse como algo exclusivo y excluyente de la vista de aquel que era considerado ajeno y extraño a nosotros (Sofsky, 2009, p. 74). Con los procesos de industrialización, el crecimiento de las ciudades y más recientemente el desarrollo de la industria del entretenimiento, el hogar empezó a ser considerado cada vez más como un espacio de descanso 
y de resolución de necesidades vitales. ${ }^{7}$ Durante 2020 empero las medidas de aislamiento social terminaron por generalizar una realidad que apenas comenzaba a asomarse a partir de la segunda década del siglo XXI cuando el desarrollo de las nuevas tecnologías de la información permitió que un sector limitado de la sociedad trasladara algunas actividades al terreno digital (Pineda 2018). No obstante, la centralidad del hogar provocada por la pandemia ha excedido el fenómeno de la migración digital al modificar toda nuestra vida social, económica y lúdica en al menos tres dimensiones: la dimensión espacio temporal; una segunda dimensión vinculada con nuestras formas de habitar el hogar; y la dimensión de las interacciones y las representaciones de nosotros y los otros. Veamos.

\subsection{La dimensión espacio-temporal}

El espacio público se ha fusionado con lo privado que hasta hace poco se había mantenido en la distinción entre la calle y la sala dividida por una puerta (Gaytán, 2013). Ahora, de manera simultanea lo público, privado e íntimo se realiza en un mismo espacio y de manera sincrónica: el comedor al que Simmel (1988, p. 323) se refirió como el espacio privado exclusivo y propio en el que se congregan los próximos en los afectos se volvió la sala de juntas, el aula de clase, la zona de fiestas online. La recámara, ese espacio de resguardo de la intimidad, terminó invadido por los otros con los que compartimos la casa o incluso se volvió también sala de trabajo. La ventana de zoom, Skype o cualquier otra plataforma destapó nuestro espacio intimo y lo mostró al mundo.

En lo que respecta a la temporalidad la distinción entre el tiempo de trabajo y el tiempo destinado al ocio terminó por desdibujarse prolongando una tendencia que venía consolidándose desde hace algunas décadas y que Guy Standing ha denominado como "La contracción del ocio" (2013, pp. 204-209). En las ciudades la reducción de los tiempos de traslado (del hogar al trabajo o a la escuela y viceversa) fue compensada por la multiplicación del tiempo dedicado a los dispositivos digitales sea para el trabajo, la escuela o incluso para actividades lúdicas. No obstante, aun en lo correspondiente al ocio o el entretenimiento, la distribución del tiempo en el hogar supuso instancias de mediación en el mejor de los casos a través de un consenso entre los miembros del hogar pero en el peor mediante la autorización de una figura jerárquica.

\subsection{La dimensión del habitar}

Además de los cambios objetivos en la gestión del espacio y el tiempo, el concepto Hogar-Mundo también permite encuadrar un cambio en nuestra forma de habitar el propio hogar. Con contadas excepciones, las casas en nuestras sociedades han sido diseñadas como simples espacios de descanso y de solución de necesidades vitales (alimentación, descanso, intimidad), no para ser habitadas todo el tiempo ni para que sus inquilinos ocupen los espa-

\footnotetext{
${ }^{7}$ Retomando a los griegos, Arendt (1998: 67-66) señaló en su momento la importancia de la separación del Oikós como espacio doméstico respecto de la polis en tanto ágora donde los hombres pueden ejercer la libertad mediante la acción política. Desde la década de1960 sin embargo la filósofa alemana advirtió que el abandono del Oikós estaba más bien signado por el ascenso de lo "social" vinculado con la tecnología, el consumo y el mercado.
} 
cios de manera simultánea (Lynch, 2008, p. 45). Las casas se han planteado pensando en que la mayor parte de la vida social se llevará a cabo en el espacio público, considerando que sólo ciertos horarios y espacios serán ocupados de manera simultanea: en el tiempo noche y mañana y en el espacio el comedor y la sala. Koolhas (2014, p. 21) en su análisis de la ciudad moderna advirtió la incapacidad de habitar el hogar pues la mayor parte las actividades se llevan a cabo al exterior donde la ciudad nunca duerme por la frenética vida social.

Durante la pandemia, las personas han tenido que convivir 7 días por 24 horas y se han traslapado horarios, se invaden o cambian el uso a los espacios. Paul Ricoeur (2003, p. 23-25) explicó que la arquitectura tenía como finalidad construir espacios habitables en los que se desplegará el espíritu humano, pero la obsesión inmobiliaria produjo el efecto de la lámpara de Aladino (encerrado, haciendo uso de lo disponible en un mismo espacio). Con la cohabitación a un mismo tiempo ha mutado el uso de los espacios donde la intimidad no tiene cabida, y lo público simplemente es algo regulado por los jefes del hogar como forma de dar sentido a un momento caótico producido por una irrupción sanitaria que obligó a todos a refugiarse y compartir un mismo espacio.

\subsection{Nosotros y los otros}

Las consecuencias del traslapamiento de lo publico y lo privado en el Hogar-Mundo no se reducen a la disposición del tiempo y el espacio, a la gestión de las nuevas tecnologías o a la materialidad de la estructura habitacional, sino que permean las interacciones y las representaciones de nosotros y los otros. Como resultado del confinamiento de la complejidad social al espacio de lo privado, el hogar se convirtió en un mecanismo de distinción entre un nosotros y los otros-extraños (los sanos frente a la amenaza de los contagiados que deambulan en la calle, la confianza en los propios frente al riesgo que representa el mundo, los responsables que atienden las indicaciones gubernamentales frente a los irresponsables que no las atienden) ${ }^{8}$

De igual forma, en el momento en que lo privado se colocó como el gran filtro del exterior favoreció una actitud de clausura hacia aquello que amenazaba al grupo. Lo privado asumió la primacía de organizar ese micro mundo, definiendo lo aceptado (Gonzalbo, 2019, pp. 131-132), los valores predominantes, los usos y costumbres, la obediencia y lealtad al grupo. Las emociones, el cuerpo como expresión de lo íntimo quedó supeditado a la vigilancia del jefe (a) del hogar o de los miembros dominantes, e igualmente lo público tendría que pasar el tamiz de la sanción moral interna. ${ }^{9} \mathrm{El}$ aumento de la violencia doméstica, los niveles de conflicto entre vecinos y los pocos márgenes de tolerancia hacia el otro cuando se sale a la calle donde se espera que los demás actúen como nosotros lo hemos hecho en casa están estrechamente vinculados con esta circunstancia. ${ }^{10}$

\footnotetext{
${ }^{8}$ En México, durante los primeros meses de la pandemia se registraron actitudes en redes sociales de reproche e incluso desprecio hacia quienes salían de casa. Esta postura ha generado un debate importante pues en un país con un 51\% de empleo informal (INEGI, 2017) el llamado a quedarse en casa sólo puede ser atendido cabalmente por un sector minoritario de la población sin poner en riesgos sus medios de subsistencia.

${ }^{9}$ Algunas encuestas reflejan este sentimiento de autoridad y control en la frase "la democracia termina donde comienza la puerta de mi casa", una de ellas refleja tal situación como la Encuesta Nacional de Cultura Política (SEGOB, 2012) y la Encuesta Nacional sobre la Dinámica Social de la Familia (SNDIF, 2011).

${ }^{10}$ De acuerdo con Naciones Unidas: “... los primeros datos muestran que los teléfonos de asistencia en Singapur
} 
Debido a las características del Hogar-Mundo se hace más patente la necesidad de regular las actividades y ritmos de convivencia, evitar la alteración y dar orden a la convivencia. Aunque las posibilidades de regulación y ordenamiento pueden ser virtualmente infinitas, no resulta difícil entender por qué el Hogar-Mundo se convierte en ambiente propicio para lo que hemos denominado aquí como Nuevos Puritanismos. Ocurre que en espacios confinados, con una regulación del tiempo sujeta a la autorización de un tercero y en donde las interacciones con los otros se reducen significativamente, las jerarquías tienen más peso y la contrastación de ideas y concepciones morales debe enfrentar el cerco de la autoridad familiar.

\section{Tutela del hogar por los nuevos puritanismos y la fuerza en el Hogar-Mundo}

La centralidad del Hogar Mundo ha propiciado el surgimiento de los nuevos puritanismos, más de carácter secular que religioso, pero igual de rígidos moralmente. Recordemos que el puritanismo histórico que aparece en Inglaterra y Escocia hacia los siglos XVI, XVII y XVIII tuvo como principales rasgos el cumplimiento moral de los valores que la religión cristiana estableció como pautas de virtud para ser dignos de la salvación a los ojos de Dios, teniendo en cuenta que la predestinación sólo era conocida por lo sagrado y no por los hombres. Las comunidades puritanas más próximas al calvinismo, buscaron ante todo cambiar, no sólo a la iglesia sino también a ellos mismos, sus familias y sus comunidades a través de estrictos códigos de comportamientos orientados a la virtud tanto en lo público como en lo privado. El cumplimiento de tales preceptos interpelaba a cada individuo, más en una dimensión ética que moral, aunque la comunidad y los censores de esta siempre estaban vigilando su cumplimiento (Walzer, 2008, p. 34)

Max Weber analizó el alcance que tal ética puritana tuvo en las condiciones económicas y sociales de la época y la afinidad electiva con el espíritu capitalista (Schluchter, 2006, p. 25). Para Weber la ética protestante (en su versión puritana) exigió a todos los que la practicaban y creían en esta forma de entender el mundo cambiar sus dimensiones de vida en tres grandes sentidos: a) Una vida coherente y disciplinada pues no hay condiciones para el arrepentimiento posterior; b) La predestinación que Dios ha establecido para cada uno es un misterio. Sólo pocos serán salvos, pero se considera que se tomarán en cuenta las obras terrenales que se realizaron en la tierra (ascetismo intramundano); c) Trabajo duro y el ahorro para la obra y gracia del Señor (Weber, 1979).

Pero los nuevos puritanismos se alejan de su interpretación de una moral evangélica para colocarse en un ámbito secular donde, si bien mantienen elementos de valores religiosos cristianos como la virtud, la culpa y el pecado, se orientan más hacia una dimensión moral estableciendo los parámetros morales a partir de sus creencias y de los valores que considera correctos. Aun cuando estas creencias y valores pueden ser compartidos

\footnotetext{
y Chipre han registrado un incremento de más del 30\% en las llamadas. En Nueva Gales del Sur (Australia), los trabajadores de primera linea comunicaron un 40\% más de solicitudes de casos de violencia. En Francia, los casos de maltrato aumentaron un 30\% desde el inicio del confinamiento el 17 de marzo. En Argentina, las llamadas de auxilio por violencia doméstica han aumentado un 35\% desde el 20 de marzo cuando se inició la cuarentena" Naciones Unidas (21 de septiembre 2020). Víctimas de violencia doméstica atrapadas durante la pandemia. Recuperado de: https://www.un.org/es/coronavirus/articles/un-supporting-trapped-domestic-violence-victims-during-covid-19-pand
} 
con quienes poseen afinidades religiosas, los nuevos puritanismos se nutren ante todo de los aspectos morales y de los juicios de valor sobre lo que acontece y lo que debería ser. En ese sentido, se trata de una cuestión ética referida a la manera en que debe comportarse el resto de las personas. De no cumplir con estas expectativas se corre el riesgo de una sanción pública señalando sus fallas y exhibiéndolas en los tribunales de las redes sociales como ha ocurrido en México y en el mundo cuando una persona es expuesta como transgresora de algo concebido como "lo correcto", sea o no cierto, sea un error involuntario o una acción deliberada. La sanción no parece dirigirse al contenido de su acción sino sobre todo a lo que provoca en otras personas.

Esta nueva versión rígida de la moral y de los comportamientos éticos es favorecida por el Hogar-Mundo. La reclusión de la vida social en la casa, la necesidad de contar con elementos de seguridad ante la amenaza de la pandemia y de los contagiados condujo a que se generaran esquemas rígidos de usos y costumbres, valores compartidos y aceptados por el grupo o los miembros del hogar. Como lo publico estaba subordinado a lo privado en el hogar y como lo íntimo estaba regulado igualmente en lo privado, la dimensión de lo privado fue organizando la vida social en el hogar, las reglas de comportamiento y la forma de ver el mundo exterior.

\subsection{Cultura de la sanción y cultura de la cancelación}

Los nuevos puritanos no enarbolan principios de salvación extra mundanos pues el seguimiento de lo que se considera correcto en el hogar es suficiente para salvaguardar la integridad de todos los miembros. Esta actitud no se restringió a sectores con códigos de conducta más tradicionales sino a grupos más extensos que propagaron sanciones éticas y de reprobación moral en las redes socio digitales a quienes eran exhibidos transgrediendo lo que se consideraba como lo correcto y lo éticamente aceptable (Pineda, 2018, p. 13). En algunos casos se propagó una exigencia de castigo para aquellos que no respetaran las normas sanitarias, como la cárcel o multas severas. ${ }^{11}$

Estas formas culturales alcanzan su pico más alto con los puritanismos de sanción secular si bien ya venían de tiempo atrás. Con la novedad de que ahora buscan propiciar un doble impacto: sobre la cultura cívica en el exterior y mediante el autoritarismo ético en el interior del hogar. En cuanto a lo exterior se han generado las formas culturales de la sanción y de la cancelación. La cultura de la sanción refiere a la predisposición inmediata de señalar y evidenciar todo aquello que sale de las normas y valores morales: salir a la calle, no usar correctamente el cubrebocas, realizar reuniones en plena pandemia, etc. La cultura de la sanción es lo que anteriormente incitaba a denunciar, señalar y exigir castigo a los infractores sin un proceso previo o un desahogo de pruebas. No obstante, en sociedades desiguales como las de América Latina esta actitud de sanción moral no suele pro-

\footnotetext{
${ }^{11}$ En Toluca, Estado de México las autoridades aprobaron sancionar con carcel a las personas que no usaran cubrebocas, al igual que en León, Guanajuato y en Cancún, Quintana Roo. El caso de Jalisco también resulta emblemático pues en su afán de criticar a las autoridades federales el gobernador de la entidad generó una retórica de manoo dura que culminó con el asesinato de una persona por parte de la policía después de ser detenido por no usar cubrebocas. Redacción. (17 de abril 2020). Uso de cubrebocas ya es obligatorio en 10 estados durante pandemia de covid-19. Diario Milenio. Recuperado de: https://www.milenio.com/estados/coronavirus-uso-del-cubrebocas-ya-es-obligatorio-en-10-entidades
} 
blematizar el privilegio de quienes desde una posición socio-económica acomodada pueden cumplir la cuarentena y seguir todos los protocolos sanitarios. ${ }^{12}$

Como consecuencia de esta proclividad a la sanción se ha expandido la cultura de la cancelación, no sólo en redes digitales sino en la convivencia en los barrios y colonias donde son señalados los infractores. Se trata de retirar el crédito moral a estas personas y además exigir la cancelación de sus actividades económicas, sociales e incluso religiosas. Así, se presiona a otros a tomar las decisiones de cancelar a los que han provocado el supuesto daño (Yoffe, 2020) Este mecanismo se ha extendido durante la pandemia para hacer valer las reglas y valores frente a quienes se consideran como los malvados morales.

\subsection{Mal y malicia}

Cabe precisar aquí que estos grupos no tienen una narrativa sobre el mal como un fenómeno provocado por entidades supra naturales, una especie de metafísica para comprender el daño generado. Para estos el mal tiene una dimensión en dos sentidos: como mal moral y como malicia (Bonete, 2017, p. 38). Por mal moral se entienden aquellas acciones que son incorrectas aun cuando las personas busquen justificarlas como aceptables, es decir, son acciones que violan los códigos morales del grupo, aunque existen razones que eximen a las personas de asumir las consecuencias (Forti, 2014, p. 67). Así, por ejemplo, algunas de las personas que transitaban en la calle en plena pandemia se sentían obligadas a justificar su acción como necesaria, ya sea por el trabajo, necesidades económicas o alguna otra razón que les permitía escapar al juicio siempre acechante de otros. Con todo, el puritanismo de nuevo cuño no deja de señalar la laxitud de su comportamiento en la calle y el riesgo de infección que ellos representaban.

Otra dimensión del mal que identifican los puritanos es la malicia, comportamientos alevosos de los individuos por buscar la máxima ganancia a costa de los demás (Bonete, 2017, p. 38). La sanción ética no proviene de cuestiones trascendentales, ni de imágenes o símbolos del mal. La sanción va directamente contra todo aquello que se interprete como malicia echando mano de criterios ortodoxos y rígidos para la aplicación moral. Se podrá notar que el concepto del mal en los nuevos puritanos no se corresponde con el tema de la predestinación de los puritanismos históricos sino con la sanción moral de lo que no se considera correcto según unos parámetros de lo éticamente aceptable que no están mediados por la otredad sino que se constituyen desde la mismidad.

La centralidad del mal moral y la laxitud para atribuir malicia a los actos ajenos se hace más patente debido a que en el Hogar-Mundo el sometimiento de la esfera de lo privado sobre lo público y lo doméstico permite sancionar los contenidos y comunicaciones externas con una efectividad hasta ahora insospechada. Aunque los padres de familia ya podían regular lo que sus hijos ven y escuchan en casa mediante diferentes procedimientos, ahora no sólo tienen la capacidad de protestar contra los contenidos escolares que les parecen inmorales sino que pueden "proteger" a sus hijos con sólo apagar la cámara y el

\footnotetext{
${ }^{12}$ Aunque en un contexto distinto y sin querer volver equivalentes dos circunstancias diferentes esta actitud nos recuerda la persecución que tanto los puritanos como los católicos realizaron contra aquellos que eran denunciados como herejes, brujas o enemigos de la religión, sólo que ahora las condiciones vienen dadas contra aquellos que moralmente consideramos son un riesgo para los demás.
} 
micrófono o silenciando las sesiones virtuales. De igual forma, en aras de una supuesta protección moral se han intensificado las restricciones en el terreno de lo íntimo mediante el control sobre el cuerpo de las mujeres o la vigilancia en las consultas médicas para obtener métodos anticonceptivos y de salud reproductiva.

\subsection{Espiritualidad y religiosidad en los nuevos puritanismos}

Los nuevos puritanos también modificaron las pautas religiosas, tanto en las formas de creencia como en las mismas prácticas. La prohibición de las reuniones públicas en los templos y la suspensión de algunos rituales, así como la cancelación de los funerales que congregaban a los deudos, ha impedido que la angustia y el miedo se mitiguen de manera colectiva. No obstante, estas limitaciones abrieron la puerta para una re-apropiación de las creencias y las prácticas religiosas.

En amplios sectores de la población mexicana la religiosidad de las personas no se orientó a una práctica individual y secular como acontece en Estados Unidos o Europa sino al fortalecimiento de la creencia grupal a través de expresiones mágicas, espirituales o metafísicas. La divulgación amplia de amuletos, aceites milagrosos y objetos protectores contra el coronavirus aun contra lo indicado por la autoridad sanitaria fue una práctica común. ${ }^{13} \mathrm{Al}$ inicio de la pandemia se ofertaron veladoras, estampas religiosas o productos milagrosos como el dióxido de cloro. Incluso si desde las jerarquías eclesiásticas se manifestó un rechazo a este tipo de creencias, en las prácticas diarias se hicieron presentes. Dentro del Hogar-Mundo las formas mágicas se mezclaron con las creencias religiosas formales dando lugar a un sincretismo religioso. Al no tener una raíz religiosa sino secular, los nuevos puritanos no tuvieron problema alguno en este tipo de sincretismos que, "si bien no ayudaban", según lo expresaron en algunas encuestas, "tampoco estorbaban" (Juárez et al., 2020, p. 24).

En la parte espiritual podemos observar que la principal búsqueda fue a través de ejercicios de meditación, ya sea yoga o cualquier otro elemento que le permitiera alcanzar lo que denominaban la paz interior, oraciones grupales, lecturas bíblicas, etc. Esto no tendría mayor novedad si no fuera porque este tipo de ejercicios comenzaron a ser reali-

\footnotetext{
${ }^{13}$ El 18 de marzo de 2020 en la conferencia matutina diaria el presidente de los Estados Unidos Mexicanos mostró un amuleto asociado al catolicismo conocido como "detente" y un trebol para la suerte que le fueron entregados en sus giras por el país. Contrario a lo registrado por algunos medios de comunicación de forma descontextualizada, la escena no implicó ni un llamado a enfrentar la pandemia con amuletos religiosos ni el preambulo de una política santaria anticientífica (de hecho la mención de estos amuletos se hizo en un contexto en el que no se estaba hablando de la pandemia). La escena es significativa porque el mandatario intenta interpelar a sectores populares en los que se entremezclan símbolos de diferentes iglesias y creencias populares de muy diversa índole formando un sincretismo en el que se difumina la división entre la religión, la espiritualidad y la superstición tal como lo da a entender el propio presidente: "Igual esto es muy común de la gente y tengo otras cosas porque no sólo es catolicismo sino también religión evangélica y libres pensadores que me entregan de todo y pues no está de más. Miren, aquí está otro detente". Gobierno de México, (18 de marzo 2020). Conferencia de prensa del presidente Andrés Manuel López Obrador 8 de marzo de 2019- recuperado de: https:// www.gob.mx/presidencia/prensa/conferencia-de-prensa-del-presidente-andres-manuel-lopez-obrador-8-de-marzo-de-2019-193799. Para contrastar las palabras del mandatario con la manera en la que la prensa consignó la noticia: Muñoz, A y Urrutia A. (18 de marzo 2020). Usa AMLO imágenes religiosas como "escudo protector" del coronavirus. Diario El Economista. Recuperado de: https://www.jornada.com.mx/ultimas/politica/2020/03/18/ usa-amlo-imagenes-religiosas-como-escudo-protector-del-coronavirus-7999.html
} 
zados en grupo, en compañía de la familia o de amigos y gente cercana. Según cifras de la Encuesta Sobre Coronavirus, Bienestar y Religiosidad poco más de 35\% lo realizaba en solitario, pero en forma grupal ya sea con amigos, familia o de otras formas alcanzaba el 42\% (Juárez et al., 2020, pp. 28-29).

En cuanto a las prácticas, las personas reforzaron la dimensión del hogar y por tanto del sentido de pertenencia que los puritanos reafirman como la condición moral superior. Los evangélicos cuyas prácticas se llevan a cabo generalmente en los hogares no tuvieron problemas en continuar sus rituales y encuentros, lo que reforzó la idea de las comunidades morales elegidas por la presencia de lo divino en el hogar, una especie de inmunidad santa por pertenencia al grupo. Los católicos en cambio, al no poder celebrar en los templos, pero tampoco en las casas optaron por algunas prácticas poco ortodoxas pero que reivindicaron el Hogar-Mundo y la potestad de los puritanos en ello. Así, por ejemplo, las diócesis de Tijuana en México, ${ }^{14} \mathrm{O}^{\prime}$ Higgins en Chile, ${ }^{15}$ Tarija y Cochabamba ${ }^{16}$ en Bolivia decidieron usar helicópteros y avionetas para rociar agua bendita sobre las casas y esparcir la bendición desde el aire.

Un aspecto relevante durante la pandemia ha sido la expansión de los discursos de superación personal y de bienestar que proliferaron en las redes digitales, ya sea en forma de frases aspiracionales o motivacionales, cadenas de oración u otros medios orientados a solicitar el bienestar. La expansión de literatura motivacional es un fenómeno anterior a la pandemia que ha generado toda una industria de la felicidad a través de un discurso de bienestar y optimismo centrado en la capacidad del individuo y su deseo de mejorar por encima de las condiciones estructurales en las que se inscribe (Davies, 2016). Sin embargo, este discurso del bienestar y la narrativa motivacional ha generado una representación social de un deber ser que se yergue como imperativo para los nuevos tiempos. Es decir, la circulación y apropiación de las frases aspiraciones y motivacionales suponen que los seres humanos debemos ser mejores personas después de la pandemia.

Los nuevos puritanos han asumido estos relatos como sermones éticos sobre los cuales se sanciona a los individuos propiciando lo que previamente denominamos como cultura de la sanción y de la cancelación. Es cierto que el llamado a la superación personal ha surgido en periodos críticos como forma de afrontar los miedos y las angustias (DidiHuberman, 1997). No obstante la industria de la superación personal busca moldear las expectativas de comportamiento para ajustarlas a una representación de la realización personal poco realista que no considera los obstáculos externos y que atribuye los éxitos y los fracasos exclusivamente al esfuerzo individual. Cuando los nuevos puritanismos recogen estos discursos suelen generar una posición inflexible sobre el comportamiento ético de corte secular de los individuos. Para ellos el mundo puede prescindir de máximas religiosas, pero no de sermones sobre el comportamiento esperado y éticamente deseado.

\footnotetext{
${ }^{14}$ Mendoza, A. (16 de abril 2020) La Arquidiócesis de Tijuana bendice desde los cielos a los enfermos de COVID-19. The San Diego Union Tribune. Recuperado de: https://www.sandiegouniontribune.com/en-espanol/ primera-plana/articulo/2020-04-16/la-arquidiocesis-de-tijuana-bendice-desde-los-cielos-a-los-enfermos-de-covid-19

${ }^{15}$ Ramírez, R.(23 de marzo 2020). Sacerdote lanza bendición desde helicóptero ante crisis por coronavirus. Publimetro. Recuperado de: https:/www.publimetro.com.mx/mx/virales/2020/03/23/sacerdote-lanza-bendicion-desde-helicoptero-ante-crisis-por-coronavirus.html

${ }^{16}$ Redacción. (10 de abril 2020) Bolivia: un cura tiró agua bendita desde un helicóptero. Diario Norte. Recuperado de: https://www.diarionorte.com/190745-bolivia-un-cura-tiro-agua-bendita-desde-un-helicoptero
} 


\section{Afinidades y diferencias entre nuevos puritanismos y neoconservadores durante la pandemia}

Si bien los nuevos puritanos tutelan hoy el hogar desde lo privado y subordinan en su ámbito los temas de lo público y lo privado en lo doméstico cabe preguntarse sobre las afinidades y diferencias que tiene con el neoconservadurismo y con algunos movimientos fundamentalistas. En este texto abordaremos la comparación con el conservadurismo y dejaremos en una tabla las comparaciones gráficas con los fundamentalismos e incluso las diferencias con los movimientos identificados como progresistas y/o liberales.

Se pensaría que ambas expresiones parten de una misma raíz y en principio la razón asiste a este argumento. Ambos parten de la idea de ordenar el mundo, establecer valores morales y prescribir comportamientos éticos frente al relativismo moral, en el caso de los neoconservadurismos; y frente las amenazas que la contaminación puede provocar en los espacios propios y familiares, en el caso de los neo-puritanos. Ambos también desafían lo que consideran la irrupción de la regulación pública en el ámbito privado y hasta en lo íntimo cuando aluden al ejercicio legal de una mujer al aborto en condiciones sanitarias óptimas, un derecho que no compete al Estado sino a Dios o a los grupos familiares y la ética que los une.

Para ambos grupos el avance de los derechos sexuales y reproductivos, la apertura sobre las orientaciones e identidades sexuales y de género e incluso el tema de los modelos de familia suponen una intervención no deseada en ámbitos de lo privado que compete a la moralidad y ética de cada grupo o de los miembros de la familia. Los temas sobre los que coinciden estas dos grandes expresiones son el cuerpo, la vida y la familia. Sin embargo, a pesar de estas similitudes existen claras diferencias que se vinculan sobre todo a su relación con el espacio público y a la búsqueda o el rechazo a ampliar su influencia a través de acciones colectivas. Veamos.

\section{1 ¿Tomar por asalto el espacio público o reinar en el espacio privado?}

Como hemos señalado, tanto los neo-conservadurismos como los neo-puritanismos buscan tutelar lo público desde lo privado. De ahí que no exista nada tan contrario a su concepción de las cosas como la famosa frase "lo privado es político" promovida por el movimiento de 1968 y por la segunda ola del feminismo para insistir en la necesidad de procesar políticamente lo que hasta entonces había sido relegado al terreno de lo privado. Sin embargo, este rechazo se materializa de distintas maneras.

Para los neo-conservadores lo privado prevalece y se debe extender en la regulación sobre lo político y las libertades de los individuos para garantizar el orden social. En cambio, para los neo-puritanos lo privado es supremo ante lo público, es decir, la pervivencia de los valores comunitarios frente a la permisividad de la diversidad no busca imponer sus marcos normativos en lo público, por el contrario, busca mantener la pureza del espacio doméstico frente a la contaminación del mundo exterior.

Aunque lo íntimo también se vuelve territorio de disputa las estrategias utilizadas son diferentes. Los neoconservadores buscan regular y conducir la gestión del cuerpo y el deseo de las personas por los valores morales o religiosos aceptados. El cuerpo pasa de ser algo sobre lo que impera la libertad de cada uno a ser una dimensión de regulación 
por parte de lo privado que tutela la esfera pública, las buenas conciencias ante el libertinaje: negar el aborto, eutanasia, reducir el sexo a una concepción binaria y desconocer las distinciones de género. Los neo puritanos en cambio controlan lo íntimo en el hogar, no necesitan exponer la buena conciencia en el exterior, simplemente establecen un control, una aduana sobre lo que se permite ingresar, ver, escuchar y hacer en el hogar. Los espacios de intimidad y el cuerpo están regulados por las normas del grupo.

La disputa por la libertad de conciencia y de información también establece distinciones entra ambos grupos. Mientras que los neo-conservadores pretenden regular la información y establecer pautas para un ejercicio de libertad de conciencia apegado a la moral dominante, ya sea a través de la educación. ${ }^{17}$ Los nuevos puritanismos no necesitan colocarse en el debate público, ni pugnar en los ámbitos legislativos. Basta con el control en el hogar sobre los contenidos que ahí circulan, apagar la tv, controlar los contenidos de internet o simplemente limitar el uso de las computadoras y gadgets. Mediante la dosificación y la vigilancia de la información se pretende que la conciencia (la libertad de opinión y expresión de los individuos) no salga del control permitido y tolerado en el hogar. Dos sucesos ilustran este punto: en mayo del 2020 la Secretaría de Cultura transmitió por internet la obra infantil "Dos príncipes" en alusión a la diversidad sexual. Este evento fue difundido en canales de la Secretaría de Educación Pública. ${ }^{18}$ Los padres de familia, y los grupos neoconservadores protestaron airadamente y reactivaron el \#hashtag ¡Con los niños No! Por su parte los padres de familia más afines a posturas neo-puritanas simplemente apagaron la computadora o cambiaron de actividad a sus hijos que nunca se dieron cuenta de la transmisión, menos aun de la polémica.

Por otra parte, los neoconservadurismos se presentan como grupos articulados en el espacio público, buscando tutelar la política desde la moral, invocando la supremacía de una creencia religiosa o de un conjunto de valores dominantes sobre cualquier expresión divergente a la que califican como minoritaria y anómica, producto de la baja densidad moral que la modernidad ha producido en los ámbitos sociales. En cambio, los neo-puritanos no se presentan como organizaciones, menos como grupos. En realidad, es una expresión fragmentaria en el que cada hogar es un espacio propicio para el planteamiento de un comportamiento ético que debe ser observado por aquellos que habitan lo doméstico. La fuerza de estos, a diferencia de los primeros, radica en que su articulación se ha dado bajo la forma de red social por la afinidad en la forma de ver el mundo y por compartir ideas y juicios sobre sucesos que consideran fuera de lo aceptable. Esta afinidad se extiende a las redes digitales donde las expresiones individuales de los nuevos puritanos se traducen en la búsqueda de sanción o la cancelación del crédito ético para una persona o institución. La multiplicación del post en las redes termina siendo viral hasta llegar a la sentencia de los infractores. Sin darse cuenta, personas de izquierda, derecha, apolíticos, agnósticos, creyentes, terminan reproduciendo el discurso

\footnotetext{
${ }^{17}$ El ejemplo más visible es el movimiento en torno al llamado "pin-parental" una iniciativa legislativa que busca que los padres de familia tengan el derecho de sancionar los contenidos que aprenden sus hijos en la escuela, así como las políticas de salud sexual y reproductiva. En los últimos 3 años en México esta iniciativa ha sido incorporada al debate legislativo en más de 10 estados, el debate más reciente ocurrió en mayo de 2020 en el Estado de nuevo León. Redacción. (11 de agosto 2020). Buscan 13 estados controlar educación sexual. Diario El Universal. Recuperado de: https://www.eluniversal.com.mx/nacion/buscan-13-estados-controlar-educacion-sexual ${ }^{18}$ Redacción (01 de junio 2020) Tuit de la Secretaría de Cultura desata comentarios homofóbicos. Diario Milenio. Recuperado de: https://www.milenio.com/cultura/secretaria-cultura-desata-comentarios-homofobicos-twitter
} 
puritano sin percatarse de haber aceptado ser parte, aunque fuera por enjuiciar un sólo evento.

La libertad religiosa es otra dimensión que llega a distanciar ambas expresiones. Para los neoconservadores la libertad religiosa no refiere a la elección de creencia o culto de los ciudadanos. Antes bien la libertad debe estar orientada a las iglesias y organizaciones religiosas para participar en el espacio públicos como un actor político capaz de incidir en la toma de decisiones que sobre leyes y políticas públicas se definan. Para los neoconservadores las iglesias son voz del bien común y la representación social de la conciencia moral de la sociedad. Esta perspectiva rompe con el principio de laicidad que, en América Latina, particularmente en México, se ha establecido al separar lo político de lo religioso, privilegiando la dimensión ciudadana sobre las creencias y feligresías. Para los neo-puritanismos el tema religioso y en especifico el de las iglesias no adquiere mayor relevancia, más aún en el momento del Hogar-Mundo donde lo religioso ha sido apropiado por los integrantes de la casa bajo formas mágicas, espiritualidades o consejos de superación personal. En realidad, para los neo-puritanos la vida se puede llevar sin religión pero no sin sermones que aludan a un principio de unidad y autoridad. Para ellos la regulación ética de los comportamientos dentro del hogar basta para marcar los límites de la libertad religiosa.

En suma, la gestión de lo público de los neoconservadores se centra en tutelar lo que acontece con la diversidad, regular las expresiones divergentes y mantener la unidad del orden moral. El principio de autoridad está sustentado en verdades supremas y no en discusiones ciudadanas que pueden ser tan relativas como las preferencias de cada persona. Los neo-puritanos en cambio ven el espacio público como la proximidad al contagio (in)moral y la contaminación por asociación con otros grupos o personas que no siguen las normas de conducta. Durante la pandemia hemos visto expresiones de intolerancia y señalamiento en redes digitales y otros medios a aquellos que no cumplen los lineamientos sanitarios y por ende morales que pueden denominarse neo-puritanas. Dado que los niveles de aceptación y tolerancia en el espacio público se ven rebasados o quebrados constantemente se enfrentan, señalan y sancionan a los demás. Finalmente, el neo-puritanismo puede ser adoptado por ciudadanos que no se identificarían con posiciones tradicionalistas, religiosas o conservadoras pero que durante la cuarentena han reivindicado una posición de superioridad moral frente a los otros que no respetaban las reglas de convivencia social en marcos sanitarios prudentes. En ello ha incidido la filosofía de la superación personal y motivacional que supone seríamos mejores personas después de la pandemia.

\section{Conclusiones}

El concepto Hogar-Mundo hace referencia a una realidad exacerbada durante la pandemia que sin embargo tendrá efectos prolongados. Su impacto produce modificaciones sustantivas en la configuración contemporánea entre las esferas público, privado e íntimo. Lo cierto es que este fenómeno de concentrar todas las actividades humanas en el hogar trajo consigo el despliegue de lo que hemos identificado como Nuevos Puritanismos los cuales han colocado lo privado por encima de las otras dos esferas y tutelado la vida social desde ahí. Las consecuencias las podremos ver en lo inmediato en nuestra cultura cívica que es nuestra referencia de los marcos de convivencia y de valores que compartimos como ciudadanos más allá de creencias y adscripciones comunitarias (Almond \&Verba, 1989). 
Tabla 1. Diferencias entre Fundamentalismos, Neo- conservadurismo, Nuevos puritanismos.

\begin{tabular}{|c|c|c|c|c|}
\hline & Fundamentalismos & $\begin{array}{c}\text { Neo } \\
\text { conservadurismos }\end{array}$ & Nuevos puritanos & $\begin{array}{l}\text { Liberales y } \\
\text { progresistas }\end{array}$ \\
\hline $\begin{array}{l}\text { Libertad de } \\
\text { conciencia }\end{array}$ & $\begin{array}{l}\text { Sanción, castigo } \\
\text { y eliminación de } \\
\text { todo margen de } \\
\text { pensamiento que no } \\
\text { este acorde a la doxa. }\end{array}$ & $\begin{array}{l}\text { Regulación y } \\
\text { orientación moral } \\
\text { y valoral de las } \\
\text { decisiones que los } \\
\text { ciudadanos asuman } \\
\text { sobre su cuerpo, vida } \\
\text { o familia. }\end{array}$ & $\begin{array}{l}\text { Control de la } \\
\text { individualidad por } \\
\text { parte del grupo } \\
\text { comunitario. Evitar } \\
\text { el contagio por } \\
\text { a asociaciómn }\end{array}$ & $\begin{array}{l}\text { Respeto a las } \\
\text { decisiones y } \\
\text { pensamientos } \\
\text { indiviudalidades } \\
\text { sobre su cuerpo, } \\
\text { vida y }\end{array}$ \\
\hline $\begin{array}{l}\text { Libertad de } \\
\text { información }\end{array}$ & $\begin{array}{l}\text { Control unitario } \\
\text { de una fuente de } \\
\text { información. } \\
\text { Sancionar la } \\
\text { comunicación } \\
\text { del exterior como } \\
\text { herejías. }\end{array}$ & $\begin{array}{l}\text { Regulación de la } \\
\text { información que } \\
\text { circula en el espacio } \\
\text { público }\end{array}$ & $\begin{array}{l}\text { Control de lo que } \\
\text { se lee, escucha } \\
\text { o se consulta en } \\
\text { la red dentro del } \\
\text { hogarCultura de la } \\
\text { cancelación. }\end{array}$ & $\begin{array}{l}\text { Acceso a la } \\
\text { información aún } \\
\text { cuando haya } \\
\text { saturación (No fake } \\
\text { news) }\end{array}$ \\
\hline Libertad religiosa & $\begin{array}{l}\text { La confesión de fe es } \\
\text { única y exclusiva }\end{array}$ & $\begin{array}{l}\text { Preponderancia } \\
\text { de la religión que } \\
\text { mayoritariamente } \\
\text { profesa el pueblo o } \\
\text { abrir la participación } \\
\text { a las iglesias para } \\
\text { purificar el espacio } \\
\text { públlico }\end{array}$ & $\begin{array}{l}\text { Se puede vivir sin } \\
\text { religión pero no sin } \\
\text { sermones. }\end{array}$ & $\begin{array}{l}\text { Libertad religiosa } \\
\text { es de los individuos } \\
\text { para participar en lo } \\
\text { público y no de las } \\
\text { organizaciones }\end{array}$ \\
\hline Gestión de lo públic & $\begin{array}{l}\text { Control de lo } \\
\text { religioso sobre lo } \\
\text { político. Sanción } \\
\text { moral pública }\end{array}$ & $\begin{array}{l}\text { Tutela de lo público } \\
\text { a partir de pautas } \\
\text { morales y de valores } \\
\text { Pánico moral }\end{array}$ & $\begin{array}{l}\text { Evitar el contagio } \\
\text { moral, exclusión del } \\
\text { mundo. Cultura de la } \\
\text { cancelación }\end{array}$ & $\begin{array}{l}\text { Pautas de inclusión } \\
\text { ade la diversidad. }\end{array}$ \\
\hline $\begin{array}{l}\text { Principio de } \\
\text { autoridad }\end{array}$ & $\begin{array}{l}\text { Leyes trascendentes } \\
\text { sobre las leyes de los } \\
\text { hombres. }\end{array}$ & $\begin{array}{l}\text { Se establecen } \\
\text { como censores } \\
\text { de las políticas } \\
\text { públicas y de las } \\
\text { manifestaciones de la } \\
\text { diversidad }\end{array}$ & $\begin{array}{l}\text { Regulan y controlan } \\
\text { el espacio privado y } \\
\text { dosifican las pautas } \\
\text { ahacia el exterior. }\end{array}$ & $\begin{array}{l}\text { Régimen de la } \\
\text { voluntad general } \\
\text { implica un Estado } \\
\text { Laico. }\end{array}$ \\
\hline $\begin{array}{l}\text { Laicidad } \\
\text { (ciudadanía) }\end{array}$ & $\begin{array}{l}\text { Ciudadanía alineada } \\
\text { con los preceptos } \\
\text { morales. } \\
\text { (Revisión del } \\
\text { concepto de teología } \\
\text { Política)' }\end{array}$ & $\begin{array}{l}\text { Privado es público y } \\
\text { debe regirse por los } \\
\text { principios y valores } \\
\text { que identifican al } \\
\text { pueblo elegido por } \\
\text { Dios. }\end{array}$ & $\begin{array}{l}\text { Hogar Mundo } \\
\text { excluye todo } \\
\text { principio de } \\
\text { ciudadanían en } \\
\text { aras de preservan } \\
\text { lo doméstico } \\
\text { comunitario. d }\end{array}$ & $\begin{array}{l}\text { Público prevalece } \\
\text { sobre cualquier } \\
\text { interés privado. }\end{array}$ \\
\hline
\end{tabular}

Tabla comparativa entre los nuevos puritanismos, fundamentalismos y conservadurismos teniendo como referencia las libertades civiles. Elaboración propia.

Lo que han dejado ver los nuevos puritanismos son varias transformaciones en lo inmediato en nuestro entorno social. Por un lado los ciudadanos se han manifestado por contar con mayor seguridad frente a las amenazas sanitarias, de violencia y morales a 
los que consideran estar vulnerables. Han expresado en diversas encuestas que prefieren sacrificar seguridad por libertad (Encuestas de valores) y desconfían de aquellos que van en la calle, el transporte público u otros espacios fuera del hogar. En algunas de ellas se revela que son los jefes de hogar que piden medidas extraordinarias y punitivas para los que no cumplieron las medidas sanitarias. Con ello hemos visto disminuir los márgenes de aceptación y tolerancia respecto a los extraños que habitan la misma ciudad y con ello los probables conflictos y tensiones lo que tendrá un impacto importante en nuestra calidad democrática.

La distinción ha sido clara en esta pandemia. El hogar tiene una autoridad sobre la cual lo publico no interviene. Es lo privado lo que organiza lo que acontece, sanciona lo que se debe hacer y establece juicios de valor que se extienden a otros hogares y se reproducen en las redes digitales. La pandemia trajo consigo una nueva edición del castillo de la pureza, edición ficticia pero que tendrá un impacto importante en nuestra forma de convivir y habitar este espacio común.

\section{Bibliografía}

Almond G \& Verba S. (1989). The civic culture, political attitudes and democracy in five nations. California. EUA: Sage Publications.

Austin, J. (1998). Se hacen cosas con palabras. Barcelona. España: Paidós Editorial.

Arendt, H. (1998). La condición humana. Barcelona: Editorial Paidós.

Augé, M. (2007). Por una antropología de la movilidad. Barcelona. España: Editorial Gedisa.

Bonete Perales, E. (2017). La maldad, raíces antropológicas, implicaciones filosóficas y efectos sociales. Madrid: Editorial Cátedra.

Bredekamp, H. (2017). Teoría del acto Icónico. España: Ediciones Akal.

Calvino, I. (1980). Si una noche un viajero. Barcelona: Editorial Bruguera.

Davies, W. (2016). La industria de la felicidad. España: Editorial Malpaso.

Didi-Huberman, G. (1997). Lo que vemos, lo que nos mira. Buenos Aires: Editorial Bordes-Manantial.

Forti, S. (2014). Los nuevos demonios, repensar hoy el mal y el poder. Buenos Aires: Ideas Edhasa Ediciones.

Gaytán Alcalá, F. (2013) Uno, todos, ninguno, el cuerpo en la distinción público y privado. En Suárez Hugo (Ed.). La sociedad de la incertidumbre, (pp. 53-78). Ciudad de México: Instituto de Investigaciones Sociales- UNAM.

Gonzalbo Aizpuro, P. (2019). Hablando de la historia: lo cotidiano, las costumbre, la cultura. México: El Colegio de México.

Encuesta Nacional de Hogares (2017) Instituto Nacional de Estadistica, Geografía e Informàtica. Recuperado de: https://www.inegi.org.mx/contenidos/programas/ enh/2017/doc/enh2017_resultados.pdf

Habermas, J. (1989). Historia y crítica de la opinión pública. Barcelona: Gustavo Gil Editorial.

Juárez N., Olivas O., Odgers, O., Ramírez R.(2020). Encuesta Sobre Coronavirus, Bienestar Y Religiosidad. Tijuana. México. El Colegio de la Frontera Norte.

Koolhaas, R. (2014). Acerca de la ciudad. Madrid: Editorial GG. 
Kuhar, R. \& David Patternote, (2018). Anti-Gender Campaigns in Europe: Mobilizing against Equality. New York: Rowman \&Littlefields

Lynch, K. (2008). La imagen de la ciudad. Barcelona: Editorial Gustavo Gili.

Pineda de Alcázar, M. (2018). La Internet de las Cosas, el Big Data y los nuevos problemas de la comunicación en el Siglo XX. Revista Mediaciones Sociales, (17), pp 1-24. Recuperado de: https://revistas.ucm.es/index.php/MESO/article/view/60190

Ricoeur, P. (2003) Arquitectura y narratividad. Arquitectónicos: Mind, Land \& Society, (3), pp. 9-29.

Sánchez Bravo-Villasante, F. (2015). Notas para una sociología del hogar, Res Mobilis. Revista internacional de investigación en mobiliario y objetos decorativos, Vol. 4, nº. 4, pp. 186-202 Consultado en: https://core.ac.uk/download/pdf/71873883.pdf

Schluchter W. (2006). El estudio originario sobre el protestantismo en su controversia. En Rodríguez Javier (Ed.). En el centenario de La ética protestante y el espíritu del capitalismo, (pp. 21-42). Madrid. España: Centro de Investigaciones Sociológicas.

Secretaría de Gobernación (2012) Encuesta Nacional sobre Cultura Política y Prácticas Ciudadanas.. Recuperado de: http://www.encup.gob.mx/es/Encup/Principales_resultados_2012.

Sistema Nacional para el Desarrollo Integral de la Familia (2011). Encuesta Nacional sobre la Dinámica de la Familia en México. Recuperado de: http://www.dif.gob.mx/ diftransparencia/media/encuestanaldinamfamiliamex2011.pdf

Soto, C., González, M. y Margarita E. (2003). Encuesta Nacional Sobre Violencia Doméstica e Intrafamiliar. Asunción. Paraguay: Centro de Documentación y Estudios.

Simmel (1988). El problema del estilo. Revista Española de Investigaciones Sociológicas, (84),pp. 319-326. Recuperado de: http://www.reis.cis.es/REIS/PDF/REIS_084_21.pdf

Sofsky, W. (2009). Defender lo privado. Valencia: Pre- Textos Ediciones.

Yoffe E. (2020). Una taxonomía del miedo. México. Revista Letras Libres, (226). Recuperado de: https://www.letraslibres.com/espana-mexico/revista/una-taxonomia-del-miedo.

Wallerstein, I. (2005). Análisis de Sistemas-Mundo. Una introducción. México: Siglo XXI Editores.

Walzer, M. (2008). La revolución de los santos, Estudio sobre los orígenes

de la política radical. Madrid: Katz.

Weber, M. (1979). La ética protestante y el espíritu del capitalismo. Barcelona: Editorial Península.

Weller. J., Gómez Contreras M., Martín Caballero, A., Ravest Tropa, J.(2020). El impacto de la crisis sanitaria del COVID-19 en los mercados laborales latinoamericanos. Santiago: Comisión Económica para América Latina y el Caribe.

\section{Referencias hemerográficas y páginas web}

Consejo Nacional para Prevenir la Discriminación. (13 de septiembre 2020). 17 de Mayo, Día Nacional de Lucha contra la Homofobia. Recuperado de: http://www.conapred. org.mx/index.php? contenido=noticias\&id=3153\&id_opcion $=\& o p=447$

Gobierno de México, (18 de marzo 2020). Conferencia de prensa del presidente Andrés Manuel López Obrador 8 de marzo de 2019- recuperado de: https://www.gob. 
$\mathrm{mx} /$ presidencia/prensa/conferencia-de-prensa-del-presidente-andres-manuel-lopez-obrador-8-de-marzo-de-2019-193799

Gobierno de México (23 de marzo 2020). Conferencia de prensa del presidente Andrés Manuel López Obrador, del 23 de marzo de 2020. Recuperado de: https://www.gob. $\mathrm{mx} /$ presidencia/galerias/conferencia-de-prensa-del-presidente-andres-manuel-lopezobrador-del-23-de-marzo-de-2020

Naciones Unidas (21 de septiembre 2020). Víctimas de violencia doméstica atrapadas durante la pandemia. Recuperado de: https:/www.un.org/es/coronavirus/articles/ un-supporting-trapped-domestic-violence-victims-during-covid-19-pand

Jiménez N.y Urrutia A. ( 23 de marzo 2020) Baja sostenida en homicidios dolosos, reporta Durazo. Diario La Jornada. Recuperado de:

https://www.jornada.com.mx/ultimas/politica/2020/03/23/baja-sostenida-en-homicidios-dolosos-reporta-durazo-6636.html

Mendoza, A. (16 de abril 2020) La Arquidiócesis de Tijuana bendice desde los cielos a los enfermos de COVID-19. The San Diego Union Tribune. Recuperado de: https:// www.sandiegouniontribune.com/en-espanol/primera-plana/articulo/2020-04-16/ la-arquidiocesis-de-tijuana-bendice-desde-los-cielos-a-los-enfermos-de-covid-19

Muñoz, A y Urrutia A. (18 de marzo 2020). Usa AMLO imágenes religiosas como "escudo protector” del coronavirus. Diario El Economista. Recuperado de: https://www.jornada.com.mx/ultimas/politica/2020/03/18/usa-amlo-imagenes-religiosas-como-escudo-protector-del-coronavirus-7999.html

Ramírez, R.(23 de marzo 2020). Sacerdote lanza bendición desde helicóptero ante crisis por coronavirus. Publimetro. Recuperado de:

https://www.publimetro.com.mx/mx/virales/2020/03/23/sacerdote-lanza-bendicion-desde-helicoptero-ante-crisis-por-coronavirus.html

Redacción. (10 de abril 2020) Bolivia: un cura tiró agua bendita desde un helicóptero. Diario Norte. Recuperado de: https://www.diarionorte.com/190745-bolivia-un-cura-tiro-agua-bendita-desde-un-helicoptero

Redacción. (17 de abril 2020). Uso de cubrebocas ya es obligatorio en 10 estados durante pandemia de covid-19. Diario Milenio. Recuperado de: https://www.milenio.com/ estados/coronavirus-uso-del-cubrebocas-ya-es-obligatorio-en-10-entidades

Redacción (01 de junio de 2020) Tuit de la Secretaría de Cultura desata comentarios homofóbicos. Diario Milenio. Recuperado de: https://www.milenio.com/cultura/ secretaria-cultura-desata-comentarios-homofobicos-twitter

Redacción (23 de julio 2020). La atención en refugios para mujeres subió $81 \%$ en los meses de confinamiento. Revista Expansión. Recuperado de: https://politica. expansion.mx/mexico/2020/07/23/la-atencion-en-refugios-para-mujeres-subio-81-en-los-meses-de-confinamiento

Redacción. (11 de agosto 2020). Buscan 13 estados controlar educación sexual. Diario El Universal. Recuperado de: https://www.eluniversal.com.mx/nacion/buscan-13-estados-controlar-educacion-sexual 